\title{
A measure of cereal market integration between Finland and European major countries
}

\author{
Liu Xing ${ }^{1)}$, Csaba Jansik ${ }^{2)}$ and Jyrki Niemi ${ }^{3)}$ \\ 1) MTT Agrifood Research Finland, Economic Research, Helsinki, Finland. \\ e-mail:xing.liu@mtt.fi \\ 2) MTT Agrifood Research Finland, Economic Research, Helsinki, Finland \\ e-mail: csaba.jansik@mtt.fi \\ 3) MTT Agrifood Research Finland, Economic Research, Helsinki, Finland \\ e-mail:jyrki.niemi@mtt.fi
}

\begin{abstract}
From take-off in January 2007 to peaks in the first half of 2008, wheat prices worldwide including Finland were doubled at the highest compared to the previous years, which known as "food crisis". Rising prices for key staples ran alarm bells. The producer price for cereal products in Finland has become much more volatile, and the price level has followed the average price in the EU more closely than earlier. This indicates that the prices have become more subject to the changes in other EU countries. Within EU, one of the key targets of the CAP is to facilitate the spatial integration of agricultural markets within the individual member states as well as within the community. In other words, on a spatially integrated market, price information should freely flow between member states. International trade and trade liberalization contribute to greater price transmission elasticities as domestic markets become better integrated into the world economy. Therefore, the integration of the Finnish cereal market in the EU has important implications for domestic agricultural policy. In EU, Germany is the most important trading partners of wheat and barley for Finland, and France is the most important consumer and producer of all cereal products in EU and the Exchange Market of cereal products MATIFF is also located in France. Thus Germany and France are the best price benchmark market for the Finnish producer to follow the prices. Our aim is to estimate the characteristics of the Finnish bread wheat and feed barley markets in relation to those of Germany and France from producer's point of view. Especially we investigate the impact of "Food Crises" on the estimates of price transmission of Finnish producer's prices in comparison to the European benchmark countries, which are Germany and France. Methodologically, we apply the threshold vector error correction model (TVECM) developed by Balke and Fomby (1997) Goodwin and Piggott (2001), Hansen and Seo (2002), to identify regimes, one of which cover the food crises period. A TVECM allows us to more accurately discern the existence of a long-term equilibrium relationship among the stochastic processes as well as test for price asymmetry. We focus attention on the estimation of the transmission elasticities in different regimes especially during the period of food crisis.

We found that the LOP held very well in the Finnish producer's cereal market with those in Germany and France. Noticeably, the speed of adjustment towards long-term equilibrium was found to be quite fast during "food crises" for both cases of feed barley and bread wheat. It implied that Finnish producer prices of cereal products were cointegrated to EU market faster and better during price escalation and the time of "food crises". It seems that "food crises" brought also opportunity for Finland to open agricultural markets, which is very important after the European market liberalized policies for the agricultural markets.
\end{abstract}

Keywords: food crisis, spatial integration, LOP, TVECM 


\section{Introduction}

Finland is the world's northernmost grain producing country. The major cereal crops in Finland include winter wheat, spring wheat, barley, rye and oats. Wheat is cultivated as both bread grain and fodder, only less half yield of which met the quality requirements for bread wheat. Therefore, the self-sufficiency of bread wheat in Finland is the lowest among all these cereal crops, thus need to import each year from other countries, mainly from other EU countries. Barley is the main crop in Finland, and normally the production is enough for domestic consumption. Barley is used mainly for fodder, and barley is also cultivated for brewing, both beer and enzyme malts. Barley is the most important grain species in Finland. All barley farmed in Finland is spring barley. The varieties used are internationally known. Barley malt is a significant Finnish export product, mainly exported to neighboring countries.

From take-off in January 2007 to peaks in the first half of 2008, wheat prices worldwide including Finland were doubled at the highest compared to the previous years, which known as "food crisis". Rising prices for key staples ran alarm bells. The producer price for cereal products in Finland has become much more volatile, and the price level has followed the average price in the EU more closely than earlier. (See Figure 1 and 2). This indicates that the prices have become more subject to the changes in other EU countries. Within EU, one of the key targets of the CAP is to facilitate the spatial integration of agricultural markets within the individual member states as well as within the community. In other words, on a spatially integrated market, price information should freely flow between member states. International trade and trade liberalization contribute to greater price transmission elasticities as domestic markets become better integrated into the world economy. Therefore, the integration of the Finnish cereal market in the EU has important implications for domestic agricultural policy. In EU, Germany is the most important trading partners of wheat and barley for Finland, and France is the most important consumer and producer of all cereal products in EU and the Exchange Market of cereal products MATIFF is also located in France. Thus Germany and France are the best price benchmark market for the Finnish producer to follow the prices.

Our aim is to estimate the characteristics of the Finnish bread wheat and feed barley markets in relation to those of Germany and France from producer's point of view. Especially we investigate the impact of "Food Crises" on the estimates of price transmission of Finnish producer's prices in comparison to the European benchmark countries, which are Germany and France. Methodologically, we apply the threshold vector error correction model (TVECM) developed by Balke and Fomby (1997) Goodwin and Piggott (2001), Hansen and Seo (2002), to identify regimes, one of which cover the food crises period. A TVECM allows us to more accurately discern the existence of a longrun equilibrium relationship among the stochastic processes as well as test for price asymmetry. We focus attention on the estimation of the transmission elasticities in different regimes especially during the period of food crisis.

\section{Procedure}

A TVECM is developed from a linear Vector Error Correction Model (VECM). In the linear VECMs even the smallest deviation from the long-run already leads to an adjustment toward the long-run relationship, whereas in the TVECMs the adjustment is assumed to be bounded to a set-up regime. The adjustment takes place only if the set-up boundary is exceeded. Balke and Fomby (1997) allow to take into consideration the two main criticisms raised against linear cointegration, and they base their adjustment process on the self-exciting threshold autoregressive model SETAR. Later, Lo and Zivot (2001) introduced TVEM, in which the linear restriction is lifted, and nonlinear and /or asymmetric adjust process to the equilibrium. Accordingly, a TVECM with three regime is presented as follows: 
$\Delta \ln P_{t}^{j}=\left\{\begin{array}{lc}A_{L}^{\prime} X_{t-1}(\beta)+\mu_{t} & \text { if } \omega_{t-1}(\beta)<\gamma^{L} \\ A_{M}^{\prime} X_{t-1}(\beta)+\mu_{t} & \text { if } \gamma^{L} \leq \omega_{t-1}(\beta) \leq \gamma^{H} \\ A_{H}^{\prime}+X_{t-1}(\beta)+\mu_{t} & \text { if } \omega_{t-1}(\beta)>\gamma^{H}\end{array}\right.$

The regressor $X_{t-1}(\beta)=\left(\begin{array}{l}1 \\ \omega_{t-1}(\beta) \\ \Delta x_{t-1} \\ \Delta x_{t-2} \\ \vdots \\ \Delta x_{t-1}\end{array}\right)$,

where $\hat{\gamma}=\left(\hat{\gamma}^{L}, \hat{\gamma}^{H}\right)$ are the estimated thresholds that segment the different regimes. $\varpi_{t-1}(\beta)=$ $\left(\Delta \ln p_{t-1}^{\text {Fin }}-\beta_{1} \Delta \ln p_{t}^{\text {Ger }}\right.$ ) for the bivariate TVECM of Finnish cereal prices and the corresponding German cereal prices and $\varpi_{t-1}(\beta)=\left(\Delta \ln p_{t-1}^{\text {Fin }}-\beta_{2} \Delta \ln p_{t}^{\text {Fran }}\right)$ for the bivariate TVECM of Finnish cereal prices and the corresponding Frence cereal prices. Setting $\beta_{i}=1, \varpi_{t-1}(\beta)$ is the price spread between Finnish cereal prices and German/French cereal prices in logarithmic form. Since both thresholds are unknown, they need to be estimated along with the remaining parameters of the model. Combining the strategy proposed by Lo and Zivot (2001) and Hansen and Seo (2001), the thresholds could be estimated through a likelihood ratio (LR) programme, in which thresholds $\hat{\gamma}=\left(\hat{\gamma}^{L}, \hat{\gamma}^{H}\right)$ are first set up as a grid search to minimize the log determinant of the residual covariance matrix of the TVECM, which is analogous to maximizing the standard LR tests (Ben-Kaabia et al. 2005). Secondly, the covariance matrices of the VECM and TVECM with one threshold and with two thresholds are computed and compared as follows:

$$
L R_{i j}=T\left(\ln \left(\operatorname{det} \hat{\Sigma}_{i}\right)-\ln \left(\operatorname{det} \hat{\Sigma}_{j}\right)\right)
$$

where $\hat{\Sigma}_{i}$ and $\hat{\Sigma}_{j}$ are the residual covariance matrices of the VECM and TVECM with the ith regime numbers varying from 0 to 3 . Thus, the first test would be a test of the linearity of the VECM against non-linearity. If the test is rejected we choose threshold vector error correction with either 1 or 2 thresholds.

\section{Data and Empirical results}

The original data consists of two groups of prices series: one group is the producer's prices of bread wheat extracted from Finland, Germany and France and the other is the group of producers' price of feed barley extracted from Finland and German as French data is not fully available All the data are obtained from the Information Centre of the Ministry of Agriculture and Forestry (TIKE), and they are transformed to logrithem form for the empirical analysis. Original data are presented in Figure 1 to 2 . 
Unit root test results suggest that all the tested prices series are integrated with order (1). However, the hypothesis of linear cointegrated in is rejected and results are not presented here due to the limited page requirement, and they can be provided upon the request. Test results of TVECM are listed as feed barley in functions (3) and (4); the result of bread wheat are presented in functions (5).

Firstly, all estimated values $\beta$ for the elasticity of producer prices from one market with respect to the other market in the function of $\varpi_{t-1}(\beta)$, are correctly signed and statistically significant: From 0.98 till unity. This suggests that variations in the German/French market are fully transmitted to the Finnish market. In other words, the law of one price holds very well having an elasticity of transmission of unity, in line with the prediction of economic theory for both tested cereal products.

Secondly, for feed barley, TVECM identified two regimes, where the typical regime where the Finnish producer's price level sustained about $10 \%$ higher than Germany/France. The extreme regime catch up the time when producer's price level in Finland stay 10\% lower than other markets, which include the period of food crises between 2007 and 2008. Clearly, the adjustment speed to the long-term equilibrium for Finnish barley farmer is faster when the barley price climbed high. However, in the most of tested period Finnish barley price still dominated by its own lags, which means domestic market played a major role in most of test period.

Thirdly, for bread wheat, the result is presented in equation (5). TVECM identified three regimes, similar to the feed barley case, Finnish bread wheat producers adjusted their speed to the long-term equilibrium to German market quite fast during the "food crises", in comparison, in the other regime, the long-term equilibrium found insignificant. Either domestic market in short-run dominates the price changes or the price change turned random walk.

$$
\begin{aligned}
& w_{t-1}=\ln P_{t-1, \text { fin }}^{b}-0.98 \ln P_{t-1, g e r}^{b} \\
& \Delta \ln P_{t, \text { fin }}^{b}=\left\{\begin{array}{lllccccc}
-0.032- & 0.26 w_{t-1}+ & 0.466 \Delta \ln P_{t-1, \text { fin }}^{b}- & 0.014 \Delta \ln P_{t-2, \text { fin }}^{b} & -0.013 \Delta \ln P_{t-1, g e r}^{b} & +0.013 \Delta \ln P_{t-2, g e r}^{b}+\varepsilon_{1 t} & w_{t-1} \leq-0.11 \\
(0.00)^{* * *} & (0.00)^{* * *} & (0.00)^{* * *} & (0.23) & (0.14) & (0.81) & \\
-0.001 & -0.000 w_{t-1} & +0.128 \Delta \ln P_{t-1, \text { fin }}^{b} & +0.08 \Delta \ln P_{t-2, \text { fin }}^{b} & +0.072 \Delta \ln P_{t-1, g e r}^{b} & +0.049 \Delta \ln P_{t-2, g e r}^{b} & +\varepsilon_{2 t} & w_{t-1}>-0.11 \\
(0.044) & (0.992) & (0.005)^{* *} & (0.001)^{* *} & (0.083) & (0.04)^{*}
\end{array}\right.
\end{aligned}
$$

$$
\begin{aligned}
& w_{t-1}=\ln P_{t-1, \text { fin }}^{b}-0.98 \ln P_{t-1, \text { Fra }}^{b} \\
& \Delta \ln P_{t, f \text { fin }}^{b}=\left\{\begin{array}{llllccc}
-0.014- & 0.155 w_{t-1}+ & 0.404 \Delta \ln P_{t-1, \text { fin }}^{b}+ & 0.084 \Delta \ln P_{t-2, \text { fin }}^{b} & +0.071 \Delta \ln P_{t-1, \text { fra }}^{b} & -0.012 \Delta \ln P_{t-2, \text { fra }}^{b}+\varepsilon_{1 t} & w_{t-1} \leq-0.091 \\
(0.00) * * * & (0.00)^{* * *} & (0.00)^{* * *} & (0.23) & (0.14) & (0.81) & \\
-0.001 & -0.009 w_{t-1} & +0.128 \Delta \ln P_{t-1, \text { fin }}^{b} & +0.085 \Delta \ln P_{t-2, \text { fin }}^{b} & +0.087 \Delta \ln P_{t-1, \text { fra }}^{b} & +0.089 \Delta \ln P_{t-2, \text { fra }}^{b}+\varepsilon_{2 t} & w_{t-1}>-0.091 \\
(0.136) & (0.257) & (0.002)^{* * *} & (0.037)^{*} & (0.00)^{* * *} & (0.00)^{* * *}
\end{array}\right.
\end{aligned}
$$


$w_{t-1}=\ln P_{t-1, \text { fin }}^{w}-\ln P_{t-1, g e r}^{w}$

$\Delta \ln P_{t, \text { fin }}^{w}=\left\{\begin{array}{llllll}-0.055- & 0.247 w_{t-1}+ & 0.346 \Delta \ln P_{t-1, \text { fin }}^{w}- & 0.041 \Delta \ln P_{t-2, \text { fin }}^{w}- & 0.07 \Delta \ln P_{t-1, \text { ger }}^{w}+ & 0.09 \Delta \ln P_{t-2, \text { ger }}^{w}+\varepsilon_{1 t} \quad w_{t-1} \leq-0.176 \\ (0.00)^{* * *} & (0.00)^{* * *} & (0.00)^{* * *} & (0.528) & (0.266) & (0.136) \\ -0.001- & 0.002 w_{t-1}+ & 0.025 \Delta \ln P_{t-1, \text { fin }}^{w}+ & 0.055 \Delta \ln P_{t-2, \text { fin }}^{w}+ & 0.049 \Delta \ln P_{t-1, \text { ger }}^{w}+ & 0.015 \Delta \ln P_{t-2, \text { ger }}^{w}+\varepsilon_{2 t} \quad-0.176<w_{t-1} \leq 0.086 \\ (0.042)^{*} & (0.82) & (0.582) & (0.266) & (0.045)^{*} & (0.537) \\ -0.002- & 0.006 w_{t-1}+ & 0.425 \Delta \ln P_{t-1, \text { fin }}^{w}- & 0.036 \Delta \ln P_{t-2, \text { fin }}^{w}- & 0.0151 \Delta \ln P_{t-1, g e r}^{w}- & 0.012 \Delta \ln P_{b-2, \text { ger }}^{w}+\varepsilon_{3 t} \quad w_{t-1}>0.086 \\ (0.813) & (0.926) & (0.103) * * & (0.764) & (0.774) & (0.972)\end{array}\right.$

(5)

\section{Conclusion}

We examined the price tranmsion elasticities between the Finnish bread wheat and feed barley markets and those in Germany and French using TVECM, which recognizes the non-stationary nature of the price data and allows for asymmetric price responses.

We found that the LOP held very well in the Finnish producer's cereal market with those in Germany and France. Feed barley and bread wheat of Finland asymmetrically cointegrated with benchmark markets. Noticeably, the speed of adjustment towards long-term equilibrium was found to be quite fast during "food crises" for both cases of feed barley and bread wheat. It implied that Finnish producer prices of cereal products were cointegrated to EU market faster and better during price escalation and the time of "food crises". It seems that "food crises" brought also opportunity for Finland to open agricultural markets, which is very important after the European market liberalized policies for the agricultural markets. 


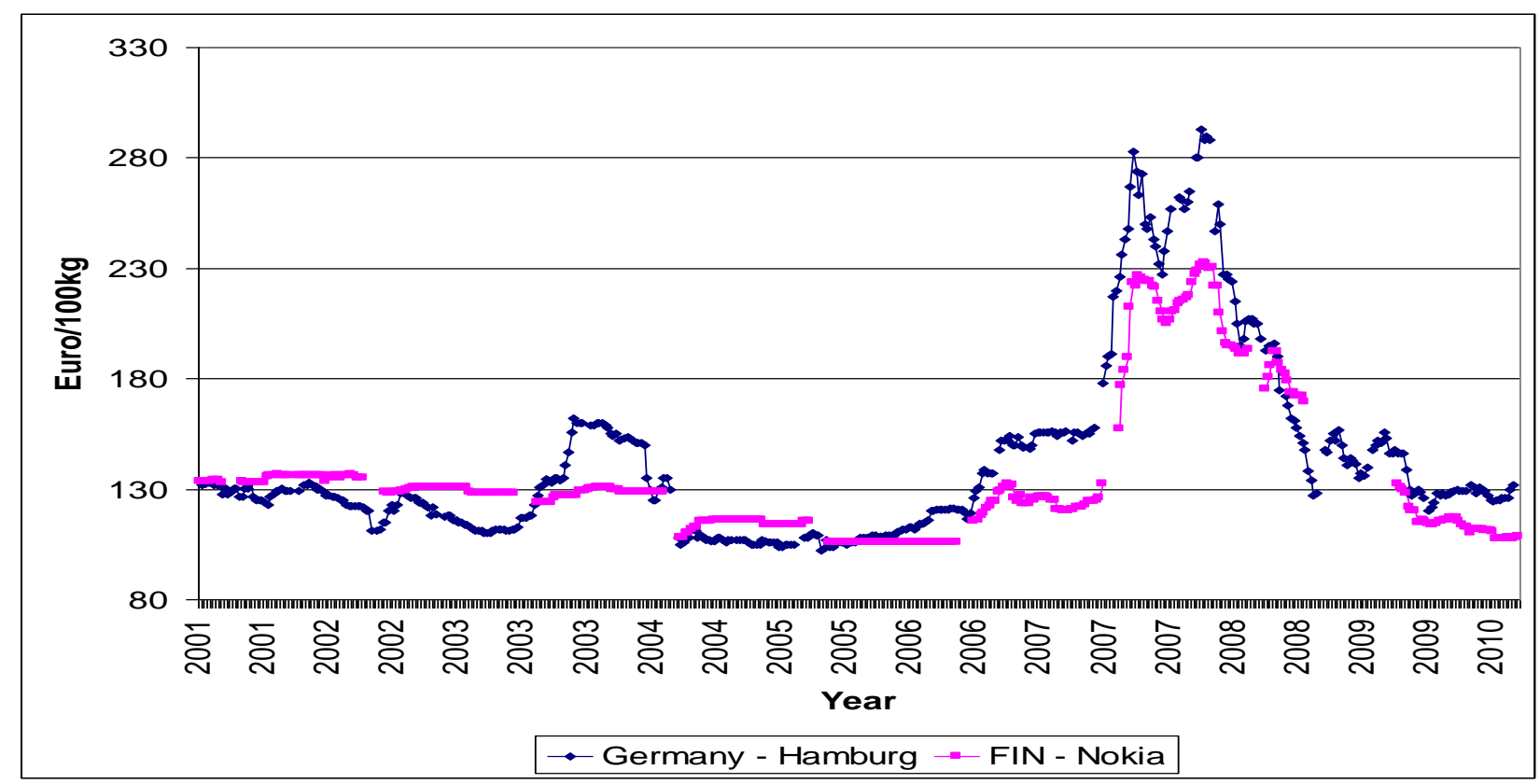

Figure 1. Original producer's prices of bread wheat from Finland and Germany

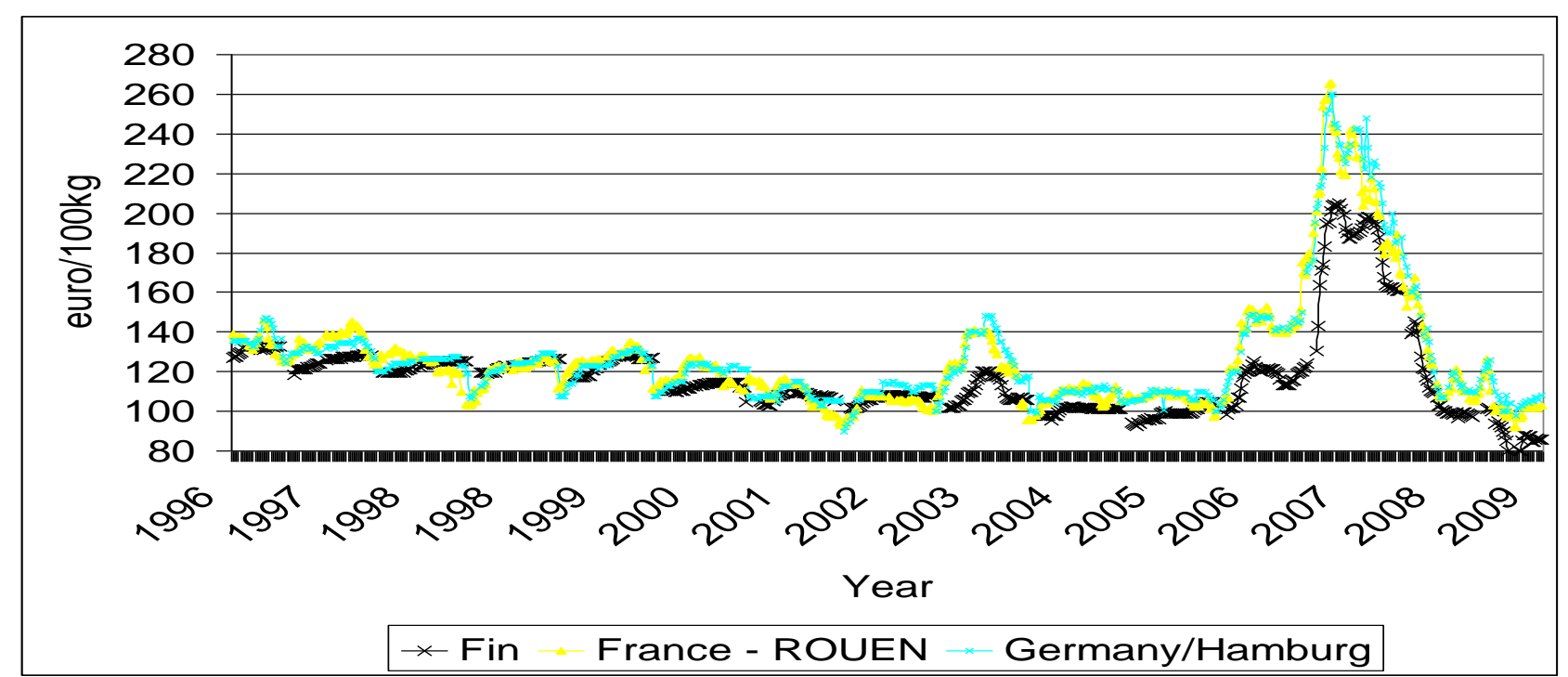

Figure 2. Original producer's prices of feed barley of Finland, Germany and France

\section{Reference}

Balke, N.S. and Fomby, T.(1997): Threshold Cointegration. International Economics Review. 38, 627-45. Ben-Kaabia M, Gil J. M. and Ameur M. (2005): Vertical Integration and Non-Linear Price Adjustments: The Spanish Poultry Sector, Vol. 21(2) 253-271.

Goodwin and Piggot N.E. (2001). Spatial market integration in the presence of threshold effects. Americal Journal of Agricultural Economics, 81, pp. 630-637.

Hansen, B. E and Seo, B (2002): Testing for two-regime threshold cointegration in vector errorcorrection models, Journal of Econometrics 110, 293-318

Lo, C., and Zivot, E. (2001). Threshold cointegration and nonlinear adjustments to the law of one price. Macroeconomic Dynamics,5, 533-576. 